\title{
PEDRO DE ANGELIS Y LA REAPROPIACIÓN DE LOS SABERES JESUÍTICOS DEL PARAGUAY. UN ESTUDIO DE LA COLECCIÓN DE OBRAS Y DOCUMENTOS RELATIVOS A LA HISTORIA ANTIGUA Y MODERNA DE LAS PROVINCIAS DEL RIO DE LA PLATA (1836-1837)
}

\author{
Nicolás Hernán Perrone \\ (CONICET/IDAES-UNSAM) \\ (Buenos Aires, Argentina) \\ ORCID: https://orcid.org/0000-0001-5783-2009 \\ nicolas_perrone@hotmail.com
}

En este trabajo analizaremos la obra del literato napolitano Pedro de Angelis Colección de obras y documentos relativos a la historia antigua y moderna de las provincias del Rio de la Plata (1836-1837) para entender las formas en que este periodista al servicio del gobernador de la provincia de Buenos Aires, Juan Manuel de Rosas, se reapropió de los saberes producidos por diversos jesuitas de la provincia del Paraguay. De Angelis publicó en la Colección una serie de obras —algunas de ellas inéditas en ese momento-de miembros de la Compañia de Jesús pero buscó utilizar los saberes geográficos e históricos recopilados en ellas para sus propios fines académico-políticos. Aqui exploraremos tanto las opiniones de este intelectual rosista sobre los jesuitas, cómo las selecciones que realizó de sus obras.

Palabras Clave: Jesuitas, Pedro de Angelis, Juan Manuel de Rosas, reapropiación, secularización.

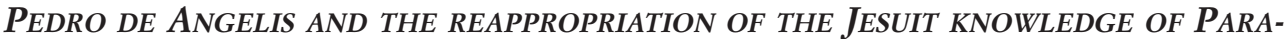 GUAY. A STUDY OF COLECCIÓN DE OBRAS Y DOCUMENTOS RELATIVOS A LA HISTORIA ANTI- gUa Y MODERNA DE laS PROVINCIAS DEL Rio de la Plata (1836-1837)}

This article analyzes the work of Neapolitan writer Pedro de Angelis, Colección de obras y documentos relativos a la bistoria antigua y moderna de las provincias del Rio de la Plata (1836-1837), to understand the ways in which this journalist at the service of the governor 
of Buenos Aires, Juan Manuel de Rosas, reappropriated the knowledge produced by various Jesuits of the province of Paraguay. In the Coleccion De Angelis published a series of works - some of them unpublished at that time- of members of the Society of Jesus but sought to use the geographical and historical knowledge gathered in them for his own academic and political purposes. The aim will be to explore both the opinions of this Rosista intellectual about the Jesuits as well as the selections be made of their works.

KEYWORDS: Jesuits, Pedro de Angelis, Juan Manuel de Rosas, reappropriation, secularization.

\section{Introducción}

Es un lugar común en la historiografía especializada remarcar la estrecha - -y muchas veces conflictiva - relación que tuvieron los miembros de la Compañía de Jesús durante la Edad Moderna con el desarrollo de las nuevas disciplinas y prácticas científicas. ${ }^{1}$ Los jesuitas fueron desde sus orígenes rápidamente asociados tanto con la producción de todo tipo de saberes académicos como con la difusión y circulación de los mismos mediante la educación que terminó siendo uno de los ministerios centrales de los jesuitas. ${ }^{2}$ La fama de los pedagogos, lingüistas, cartógrafos y matemáticos ignacianos — por nombrar sólo algunas disciplinas- de la Compañía se difundió velozmente por Occidente junto con la reputación de sus centros de educativos. En esta misma línea, los misioneros de la Compañía desperdigados por el Orbe proveyeron de novedosas informaciones sobre los desconocidos pueblos de Asia y América a las élites intelectuales europeas. ${ }^{3}$

Sin embargo, los jesuitas no cultivaron esta serie de saberes por sí mismos, sino que subordinaron siempre su desarrollo al progreso de sus ministerios religiosos. El aprendizaje de las lenguas de los pueblos de misión, así como el conocimiento de los accidentes geográficos, la flora y la fauna de los territorios donde se ejercían los ministerios apostólicos estuvieron supeditados a mejorar los procesos de adaptación y acomodación de los misioneros dentro de las prácticas de evangelización. ${ }^{4}$ Los saberes producidos en el terre-

1. Por ejemplo, es conocida la intervención de varios matemáticos de la orden — siendo Christophorus Clavius del Colegio Romano el más famoso de ellos— en el caso Galileo. Wallace O. P., William, «Jesuit Influences on Galileo's Science», en O’Malley S. J., John; Gauvin Alexander Bailey; Steven J. Harris y Frank Kennedy S. J. (eds.), The Jesuits II. Culture, Science and the Arts, 1540-1773, Toronto, University of Toronto Press, 2006, pp. 314-335; Feingold, Mordechai, Jesuit Science and the Republic of Letters, Cambridge, The MIT Press, 2003.

2. Giard, Luce (dir.), Les jésuites à la Renaissance. Système éducatif et production du savoir, Paris, PUF, 1995.

3. Desde hace tiempo que la historiografía especializada está discutiendo la idea de que los trabajos de los misioneros jesuitas sobre diversos pueblos extraeuropeos ayudaron a configurar en Europa una mirada protoantropológica. Para el caso del Paraguay ver, por ejemplo, Wilde, Guillermo, Religión y Poder en las misiones de guaranies, Buenos Aires, Ediciones SB, 2009.

4. Para un estudio sobre las diversas formas de utilización de los saberes dentro de la Compañía de Jesús 
no misional no eran aprovechados solamente in situ, sino que circulaban dentro de la propia Compañía de Jesús. Las universidades y colegios jesuitas a lo largo del Globo recibían información de primera mano de los misioneros. Allí otros sacerdotes de la Compañía estudiaban, recopilaban y editaban estos datos para producir nuevas obras como Gramáticas, Diccionarios o Historias Naturales que eran, a su vez, utilizadas para la formación de nuevas camadas de misioneros. ${ }^{5}$ Simultáneamente, estas obras producidas a partir de la base de los conocimientos adquiridos en las misiones eran también utilizadas por los ignacianos como una forma de publicitar sus ministerios y mostrar al mundo una imagen triunfante de la Compañía. De esta manera, gracias a una agresiva campaña de propaganda, los jesuitas fueron prontamente reconocidos como poseedores tanto de una especial y efectiva praxis misional, como de una serie de saberes académicos que los distinguían frente a otras órdenes religiosas. ${ }^{6}$

Los miembros de la provincia jesuítica del Paraguay — que comprendía aproximadamente los actuales territorios de Argentina, Paraguay, Uruguay y el sur de Bolivia y Brasil- fueron escritores particularmente prolíficos de este tipo de obras. Sólo en el siglo XVIII podemos mencionar a numerosos misioneros que produjeron todo tipo de escritos sobre sus tierras de misión: Buenaventura Suárez, Pedro Lozano, José Sánchez Labrador, Joaquín Camaño o José Quiroga, por nombrar sólo algunos ejemplos. ${ }^{7}$ Una gran parte de estos sacerdotes fueron víctimas de la Pragmática Sanción de 1767 de Carlos III que expulsó a la Compañía de Jesús de los reinos de España. No obstante, en muchos casos, si bien el extrañamiento los alejó de sus ministerios no provocó necesariamente un cese de sus prácticas académicas; varios jesuitas del Paraguay —así como de otras provincias - continuaron escribiendo en el exilio sus obras, cuyos contenidos provenían de sus experiencias misionales. ${ }^{8}$

Ahora bien, ¿cuál era el objetivo de estos sacerdotes al continuar produciendo este tipo de trabajos luego de la expulsión de la Compañía? En primer lugar, la tradición propagandística jesuítica se vio fortalecida debido a la necesidad que muchos de estos sacerdotes tuvieron de salir a defender a su extinta orden: las obras que ellos producían no

ver Wilde, Guillermo (ed.), Saberes de la conversión. Jesuitas, indígenas e imperios coloniales en las fronteras de la Cristiandad, Buenos Aires, Ediciones SB, 2011.

5. Harris, Steven, «Mapping Jesuit Science: The Role of Travel in the Geography of Knowledge», en O’Malley S. J., John; Gauvin Alexander Bailey; Steven J. Harris y Frank Kennedy S. J. (eds.), The Jesuits. Culture, Science and the Arts, 1540-1773, Toronto, University of Toronto Press, 1999, pp. 212-240.

6. Betrán Moya, José Luis (ed.), La Compañia de Jesús y su proyección en el mundo hispánico durante la Edad Moderna, Madrid, Sílex, 2010.

7. El principal biógrafo de estos misioneros fue el historiador jesuita argentino Guillermo Furlong. A pesar del carácter apologético de muchos de sus escritos los datos que proporciona en sus obras continúan siendo invaluables para la reconstrucción de la vida de estos sacerdotes. Algunos ejemplos de estas obras son: Furlong, Guillermo, José Sánchez Labrador y su «Yerba Mate» (1774), Buenos Aires, Librería del Plata, 1960; Furlong, Guillermo, Pedro Lozano y sus «Observaciones a Vargas» (1750), Buenos Aires, Libreria del Plata, 1959; Furlong, Guillermo, El Padre José Quiroga, Buenos Aires, Peuser, 1930.

8. Sobre la vida cultural de los jesuitas hispanoamericanos ver Batllori, Miguel, La cultura hispano-italiana de los jesuitas expulsos, Madrid, Gredos, 1966 y Guasti, Niccolo, L'esilio italiano dei gesuiti spagnoli. Identita, controllo sociale e pratiche culturali (1767-1798), Roma, Edizioni di Storia e Letteratura, 2006. 
sólo servían para demostrar méritos personales, sino también los de toda una perimida institución. Por otra parte, luego de la expulsión muchos jesuitas comenzaron a participar de los circuitos literario-académicos de la Europa ilustrada; el fin de los controles impuestos por sus superiores dentro Compañía de Jesús les dio la libertad de participar en debates dentro de la República de las Letras. Un ejemplo de esto fue la intervención de numerosos jesuitas americanos en la «Disputa del Nuevo Mundo», en defensa de la naturaleza, historia y los habitantes del continente americano. Fue la propia corona española la que reclutó la pluma de muchos ignacianos para defenderse de los ataques de pensadores ilustrados como Guillaume-Thomas Raynal, Cornelius de Pauw o William Robertson. ${ }^{9}$ Podemos afirmar entonces que los saberes jesuitas estuvieron en este periodo tanto al servicio del poder estatal como de la apologética religiosa.

Por otra parte, muchos de estos jesuitas de la provincia del Paraguay mantuvieron un estrecho contacto con las tierras de las cuales fueron expulsados mediante la construcción de una serie de redes — basadas en el intercambio epistolar — con familiares, amigos y miembros de las élites político-religiosas americanas..$^{10}$ Dentro de estas redes filojesuíticas que se desarrollaron a lo largo del territorio del Virreinato del Río de la Plata - y que continuaron con relativa estabilidad durante las primeras décadas del siglo XIX- circulaban noticias político-religiosas sobre el continente europeo y el futuro de la Compañía de Jesús, objetos artísticos y litúrgicos, pedidos de favores y ayudas monetarias. De la misma manera, junto a las cartas que cruzaban el Atlántico iban adjuntos fragmentos manuscritos, comentarios y opiniones de muchas de las obras de los jesuitas producidas en el exilio, así como menciones sobre la difusión de las mismas de manera impresa. ${ }^{11}$ Gracias a esta correspondencia podemos saber que estas obras no sólo eran bien recibidas sino que en muchos casos eran activamente demandadas por las élites locales en el Río de la Plata. Quizás uno de los ejemplos más interesantes del impacto de las obras de los jesuitas del Paraguay en la región luego de la expulsión fue el influjo que los historiadores jesuitas como José Guevara, Pedro Lozano, Domingo Muriel o Francisco Javier Charlevoix tuvieron en el Ensayo de la historia civil del Paraguay, Buenos Aires y Tucumán de Gregorio Funes impreso en 1816. Esta fue la primera obra que buscó ofrecer a sus lectores una breve historia del proceso revolucionario local — comenzado sólo seis años antes- enmarcada dentro de la larga historia colonial del Río de la Plata. ${ }^{12}$

9. Cañizares Esguerra, Jorge, Cómo escribir la historia del Nuevo Mundo. Historiografías, epistemologías e identidades en el mundo del Atlántico del siglo XVIII, México DF, Fondo de Cultura Económica, 2007.

10. Un ejemplo de estas cartas son aquellas enviadas por el jesuita santiagueño Gaspar Juárez al comerciante cordobés Ambrosio Funes en las últimas décadas del siglo XVIII. Grenon, P., Los Funes y el P. Juárez, Córdoba, La Guttemberg, 1920.

11. Algunos de los trabajos que eran mencionados frecuentemente en estas cartas son, por ejemplo, la Carta Crítica sobre la Historia de América del señor D. Juan Bautista Muñoz (1798) de Francisco Javier Iturri, la Carta dirigida a los españoles americanos por uno de sus compatriotas (1799) de Juan Pablo Viscardo o la Venida del Mesías en Gloria y Majestad Observaciones de Juan Josafat Bem-Ezra, bebreo-cristiano: dirigidas al sacerdote Cristofilo (1812) de Manuel Lacunza.

12. Para una biografía de Gregorio Funes que reconstruye el ambiente religioso e intelectual de su vida y obra ver Lida, Miranda, Dos ciudades y un deán. Biografía de Gregorio, 1749-1829, Buenos Aires, Eudeba, 2006. 
Los saberes jesuíticos continuaron siendo demandados en la región entrado ya el siglo XIX varias décadas después de la expulsión local de la Compañía de Jesús. En este trabajo estudiaremos concretamente el proceso de reapropiación de varias obras y escritos de jesuitas provenientes de la provincia del Paraguay realizado por el publicista napolitano Pedro de Angelis en uno de sus trabajos más importantes: la Colección de obras y documentos relativos a la historia antigua y moderna de las provincias del Río de la Plata. ${ }^{13}$ En las siguientes páginas buscaremos analizar las formas en que de Angelis resignificó para sus propios fines académico-políticos los saberes que los jesuitas paraguayos proveían en sus trabajos y la imagen sobre los ignacianos que construyó este polémico intelectual.

\section{El retorno fallido de los jesuitas a Buenos Aires: Juan Manuel de Rosas y la Compañía de Jesús}

Antes de adentrarnos en la obra de Pedro de Angelis será necesario decir algunas palabras sobre el regreso de los jesuitas a Buenos Aires en la década del treinta del siglo XIX durante el gobierno de Juan Manuel de Rosas.

La Compañía de Jesús fue restaurada en 1814 durante el pontificado de Pio VII en pleno proceso europeo de restauración absolutista. Un año después Fernando VII convocó a los jesuitas a regresar a España y América. No obstante, debido a los procesos de independencia americanos pocos jesuitas pudieron regresar al continente en ese momento. Recién a partir de las décadas del treinta y cuarenta la Compañía de Jesús intentó reinstalarse en el Nuevo Mundo aunque no siempre con éxito. Luego de casi setenta años de ausencia, los sacerdotes ignacianos fueron convocados por el gobernador de la provincia de Buenos Aires, Juan Manuel de Rosas en 1836. No obstante, los jesuitas que regresaron al Río de la Plata nunca habían tenido contacto directo con las tierras de la antigua provincia jesuítica del Paraguay. Estos sacerdotes eran todos de origen español y aprovecharon la invitación del gobernador Rosas para escaparse de las persecuciones religiosas que se estaban desarrollando en España lideradas por el gobierno liberal del momento. ${ }^{14}$

A pesar de haber sido Rosas quien convocó a los miembros de la ya restaurada Compañía de Jesús a regresar a Buenos Aires, las relaciones entre los jesuitas y el gobernador federal no fueron sencillas. El gobernador de Buenos Aires poseía una concepción regalista del poder y consideraba a la Iglesia y al clero como una herramienta más de gobierno y control de la sociedad. ${ }^{15}$ Los jesuitas españoles que habían aceptado gustosamente la

13. De Angelis, Pedro, Colección de obras y documentos relativos a la historia antigua y moderna de las provincias del Rio de la Plata ilustrados con notas y disertaciones por Pedro de Angelis, Buenos Aires, Imprenta del Estado, 1836-39, 6 tomos.

14. Revuelta González, Manuel, «Capítulo VIII. Sesenta años de reapariciones inestables (1815-1874)», en Egidio, T., Los jesuitas en España y el mundo bispánico, Marcial Pons, Madrid, 2004, pp. 291-312.

15. Di Stefano, Roberto, «El laberinto religioso de Juan Manuel de Rosas», Anuario de Estudios Americanos, núm. 63-1, 2006, Sevilla, pp. 19-50. 
invitación de Rosas no tardaron mucho tiempo en percibir los deseos de control de Juan Manuel de Rosas. ${ }^{16}$ Prontamente el gobierno rosista comenzó a reclamar la fidelidad de los jesuitas y a demandarles que predicaran en favor del gobierno. De la misma manera, Rosas limitó la movilidad de los sacerdotes y les prohibió salir de la ciudad y los alrededores, salvo para la realización de algunas cortas misiones volantes, coartando sus planes de expansión y de retorno a las antiguas misiones del Paraguay. ${ }^{17}$

Cuando los ignacianos rechazaron los pedidos de participar en la propaganda gubernamental, Rosas inició una fuerte campaña difamatoria contra ellos acusando a los jesuitas de estar coligados con sus enemigos políticos. En esta empresa participaron numerosos funcionarios del gobierno, incluido Pedro de Angelis sobre el cuál hablaremos en el próximo apartado. ${ }^{18}$ Finamente, luego del aumento de las presiones y adivinando un desenlace no muy amigable con el gobierno rosista, los jesuitas decidieron marcharse de Buenos Aires en 1843 para emprender otros proyectos misionales en países limítrofes. Sólo regresaron a Buenos Aires luego de la caída de Rosas, esta vez gracias a la invitación de Santiago Derqui durante su paso por la primera magistratura de la Confederación Argentina. ${ }^{19}$

\section{La Colección de documentos de Pedro de Angelis y la reapropiación de los saberes de los jesuitas del Paraguay}

Aún antes de su fallido retorno a Buenos Aires, la fama y el prestigio de los jesuitas circulaba por la región. Sus trabajos académicos, sus actividades misionales y educativas eran recordados por muchos, gracias, en gran medida, a las redes filojesuíticas creadas a finales del siglo XVIII luego de la expulsión. Sin embargo, fueron los trabajos de un intelectual europeo que trabajó durante más de treinta años en el Río de la Plata los que volvieron a poner en primera linea en Buenos Aires a las obras de los jesuitas expulsos. Nos estamos refiriendo al publicista napolitano Pedro de Angelis.

Este letrado estrechamente asociado con el gobierno de Juan Manuel de Rosas llegó a las costas del Río de la Plata en 1827 invitado por Bernardino Rivadavia —quien en ese entonces era presidente de las Provincias Unidas del Río de la Plata— para trabajar en un

16. Pérez, Rafael, La Compañia de Jesús restaurada en la República Argentina y Chile, el Uruguay y el Brasil, Barcelona, Imprenta de Henrich, 1901, p. 69.

17. Di Stefano, Roberto, «El laberinto religioso..., cit., p. 35.

18. Muchos de los ataques del gobierno rosista a la Compañía de Jesús estuvieron fuertemente enraizados en una serie de prejuicios centenarios antijesuíticos como, por ejemplo, el que acusaba a los sacerdotes de la orden de ser hábiles manipuladores de mujeres. Di Stefano, Roberto, «El antijesuitismo porteño del siglo XIX», en Monreal, Susana; Sabina Pavone y Guillermo Zermeño (eds.), Antijesuitismo y filojesuitismo. Dos identidades ante la Restauración, México DF, Universidad Iberoamericana, 2014, pp. 167-190.

19. Para una historia del conflicto entre Rosas y los jesuitas ver: Castagnino, Raul, Rosas y los jesuitas, Buenos Aires, Pleamar, 1970 y Esteban, Rafael, Como fue el conflicto entre los Jesuitas y Rosas, Buenos Aires, Plus Ultra, 1971. Ambas obras ofrecen a su vez un resumen del relato ofrecido por Pérez, Rafael La Compañia de Jesús..., cit. 
par de periódicos dirigidos por el gobierno bonaerense. Luego del colapso del gobierno de este último, de Angelis se adaptó rápidamente a los cambios políticos de la provincia y pasó a trabajar para Juan Manuel de Rosas. Previamente en Europa había tenido una agitada carrera académica. En Nápoles —en donde nació en 1784- fue tutor de los hijos de Joaquín Murat y diplomático de bajo rango para el Imperio ruso. Luego de la caída del Imperio napoleónico estuvo inserto en el ambiente intelectual parisino — cercano, por ejemplo, a Jules Michelet - siendo uno de los primeros intelectuales que introdujo las ideas de Giambattista Vico. Fue a causa de su reputación académica y sus ideas liberales que fue convocado por Rivadavia para participar del naciente campo cultural de las Provincias Unidas del Río de la Plata. Durante el gobierno rosista llevó a cabo numerosos proyectos literarios, académicos y periodísticos —algunos promovidos desde el Estado y otros por su propio interés personal-y administró la Imprenta del Estado, siendo simultáneamente propietario de la Imprenta de la Independencia. ${ }^{20}$ Debido a su íntima relación con el gobierno de Rosas de Angelis fue siempre despreciado por una gran parte de la intelectualidad opositora porteña, en particular por los miembros de la Generación del 37. Luego de la caída del gobernador de Buenos Aires, comenzó el rápido declive de la carrera académica de Pedro de Angelis. Durante los últimos años de su vida tuvo que ir vendiendo por partes su biblioteca y archivo personal al Imperio del Brasil debido a dificultades económicas. ${ }^{21}$ Falleció en Buenos Aires en 1859. ${ }^{22}$

Puntualmente para este trabajo nos interesa estudiar uno de sus trabajos más importantes, la Colección de obras y documentos relativos a la historia antigua y moderna de las provincias del Rio de la Plata en la cual de Angelis publicó entre los años 1836 y 1837 a lo largo de seis tomos una serie de obras en torno a la geografía, naturaleza e historia de la región. Este emprendimiento fue la primera compilación historiográfica de la historia cultural y editorial argentina; con el mismo de Angelis buscaba explorar el pasado del Río de la Plata y rescatar del olvido una serie de documentos hasta el momento desconocidos - la gran mayoría de las obras publicadas en estos tomos se encontraban inéditas al momento de la aparición de la Colección — para enlazarlos simbólicamente con el presente del gobierno rosista..$^{23}$

20. Para el caso de la Colección que estudiaremos en las próximas páginas es necesario aclarar que si bien fue un proyecto académico personal de de Angelis la misma fue publicada en la Imprenta del Estado que administraba el napolitano.

21. Durante toda su vida de Angelis fue acusado por sus enemigos de robar documentación de los archivos estatales para sus fines académicos personales. Baltar, Rosalía, Letrados en tiempos de Rosas, Mar del Plata, Eudem, 2012, pp. 87-92.

22. El trabajo, sin dudas, más completo sobre la vida y obra de Pedro de Angelis es Sabor, Josefa, Pedro de Angelis y los orígenes de la bibliografía argentina. Ensayo bio-bibliográfico, Buenos Aires, Ediciones Solar, 1995. Para otros trabajos relevante sobre la carrera intelectual de de Angelis, ver Ruggeri, Paula, «Estudio preliminar», en de Angelis, Pedro, Archivo Americano y espiritu de la prensa del mundo. Primera Serie 18431847, Buenos Aires, Ediciones Biblioteca Nacional, 2009, pp. 9-36; Mercado, Juan Carlos, «Pedro de Angelis y la historia intelectual argentina de la primera mitad del siglo XIX», Hesperia. Anuario de filología hispánica, XVI2, 2013, pp. 59-72.

23. Baltar, Rosalía, Letrados en tiempos..., cit., pp. 116-129. 
Los trabajos editados dentro de cada uno de estos tomos fueron, en su mayoría, organizados temática o geográficamente. ${ }^{24}$ Para cada uno de ellos el literato italiano ofrece, generalmente, una breve introducción sobre su contexto de producción y su autor. $\mathrm{Mu}$ chos de los papeles y escritos que editó de Angelis provenían tanto de archivos públicos como privados de Buenos Aires, siendo su principal proveedor de documentación el clérigo Saturnino Segurola, uno de los primeros directores de la Biblioteca Nacional de Argentina. ${ }^{25}$ Ahora bien, una de las fuentes de información más importantes para de Angelis en el armado de su Colección fueron las producciones literarias de los miembros de la Compañía de Jesús. En las próximas páginas intentaremos ver de que manera el napolitano se reapropió de las obras y saberes jesuíticos y con que fines.

Primeramente, hay que destacar que el contacto de Pedro de Angelis con los jesuitas no fue solamente a través de sus obras o documentos. Cuando los sacerdotes ignacianos arribaron a Buenos Aires y comenzaron con sus tareas educativas en la ciudad tuvieron que editar prontamente libros de texto para sus estudiantes. Es así como recurrieron a la Imprenta del Estado administrada por el periodista napolitano cruzando caminos con él. De Angelis aprovechaba sus contactos con los ignacianos en la imprenta para transmitirles los pareceres del gobierno sobre su accionar y difundir sus campañas de desprestigio. ${ }^{26}$

Sin embargo, el napolitano también se acercó a los ignacianos por motivos personales, según relata el historiador jesuita Rafael Pérez retomando los comentarios del provincial de la nueva misión bonaerense, Manuel Berdugo:

Este caballero, napolitano avecindado de muchos años atrás en Buenos Aires, era hombre de mundo y muy amigo de Rozas, por tener a cubierto su vida e intereses, como lo era de los Jesuitas por la razón sobredicha y porque le proporcionaban datos sobre las antiguas misiones del Paraguay. ${ }^{27}$

En las próximas páginas veremos las razones del interés de de Angelis en el pasado misional de la Compañía de Jesús en la región.

Son varios los escritos de miembros de la Compañía que fueron editadas en la Colección de de Angelis. ${ }^{28}$ En el Tomo I se encuentran la primera traducción al castellano de la

24. Por ejemplo, dentro de un tomo pueden encontrarse juntas varias obras dedicadas al Chaco o a la Patagonia. De la misma manera, el Tomo IV está íntegramente dedicado al Tratado de Límites de 1750 firmado por las coronas de España y Portugal.

25. De Angelis agradeció a Segurola en la mayoría de las introducciones de su Colección. Por otra parte, este sacerdote también fue una fuente importante de información documental para Gregorio Funes durante la escritura de su Ensayo de Historia Civil como él mismo reconoce: «Nada iguala al deseo de este erudito eclesiástico, por enriquecer su espíritu de conocimientos útiles, sino su exquisita diligencia en adquirirlos». Funes, Gregorio, Ensayo de Historia Civil del Paraguay, Buenos-Ayres y Tucumán escrita por el doctor D. Gregorio Funes, deán de la Catedral de la Santa Iglesia de Córdoba, Imprenta Gandarillas, Buenos Aires, 1816, p. VII.

26. Pérez, Rafael, La Compañia de..., cit., p. 206.

27. Ibidem, pp. 208-211.

28. En total, más de cincuenta obras y documentos de todo tipo fueron publicados a lo largo de los seis tomos de la Colección. 
Descripción de la Patagonia y de las partes adyacentes de la América Meridional de Tomás Falkner que había sido originalmente publicada en inglés casi setenta años antes ${ }^{29}$ y el Diario de un viaje a la costa de la mar magallánica en 1745, desde Buenos Aires hasta el Estrecho de Magallanes. Formado sobre las observaciones de los PP. Cardiel y Quiroga siendo este último una reimpresión de un fragmento de la obra de Histoire du Paraguay de Pierre François Xavier Charlevoix originalmente publicada en francés en $1762 .{ }^{30}$ En el siguiente tomo de Angelis editó por primera vez la Historia del Paraguay, Río de la Plata y Tucumán de José Guevara junto con la Descripción del Rio Paraguay, desde la boca del Xauru hasta la confluencia del Paraná de José Quiroga. Si bien en los tomos tres y cuatro de la colección no fue publicado ningún trabajo escrito por jesuitas, las menciones a los mismos y su accionar en la región en las introducciones de los documentos editados son numerosas. El tomo cuatro, por ejemplo, está dedicado al Tratado de Límites siendo ineludible la referencia a la intervención de los jesuitas en el mismo y en la posterior Guerra Guaranítica. En este sentido, dentro del tomo cinco de Angelis editó — también por primera vez- el Diario bistórico de la rebelión y guerra de los pueblos guaranís, situados en la costa oriental del río Uruguay, del año 1754 siendo una traducción al castellano de la obra latina de Tadeo Javier Henis. Finalmente, en el sexto tomo si bien tampoco hay publicada ninguna obra escrita por jesuitas, existen numerosas menciones a estos sacerdotes y sus emprendimientos misionales en la Patagonia o el Chaco.

Ahora bien, ¿cuál era la opinión que Pedro de Angelis tenía sobre los miembros de la Compañía de Jesús y sus trabajos apostólicos en la región?

A pesar de sus orígenes políticos liberales, se puede observar en sus escritos una simpatía poco disimulada por los miembros de la Compañía de Jesús. Particularmente ilustrativo de esto es su posición respecto a un evento crucial de la historia de los jesuitas: su expulsión de España y América por parte de Carlos III en 1767. El periodista rosista descreía profundamente de los mitos antijesuíticos construidos en torno a las causas de la expulsión:

Las relaciones que se publicaron para justificar su supresión, no merecen crédito, por el espíritu que presidió á su redacción y el objeto que se propusieron los que las divulgaban. Ninguno de los miembros de aquella orden famosa se empeñó en rebatir estas calumnias: sea que los desalentase la desgracia; sea por la necesidad que sienten los que sufren males inmerecidos de buscar algún alivio en objetos nuevos y fantásticos. ${ }^{31}$

29. Falkner, Thomas, A Description of Patagonia and the Adjoining Parts of South America: containing an Account of the Soil, Produce, Animals, Values, Mountains, Rivers, Lakes, and etc. of those Countries; the Religion, Government, Policy, Customs, Dress, Arms, and Language of the Indian Inhabitants; and some Particulars relating to Falklands Islands, London, Hereford, 1774.

30. De Angelis, Pedro, «Advertencia del editor» del Diario de un viaje a la costa de la mar magallánica en 1745, desde Buenos Aires hasta el Estrecho de Magallanes. Formado sobre las observaciones de los PP. Cardiel y Quiroga por el P. Pedro Lozano en de Angelis, Pedro, Colección de obras y documentos relativos a la bistoria antigua y moderna de las provincias del Rio de la Plata ilustrados con notas y disertaciones por Pedro de Angelis, Buenos Aires, Imprenta del Estado, tomo primero,1836, p. II.

31. De Angelis, Pedro, «Discurso preliminar» de la Memoria histórica, geográfica, política y económica sobre la provincia de Misiones de indios guaranís, por D. Gonzalo de Doblas, teniente gobernador, en de Angelis, 
Una de las obras contra los ignacianos más famosas del periodo fue el Reino Jesuitico del Paraguay escrita por el sacerdote Bernardo Ibáñez de Echavarri en 1762. ${ }^{32}$ De Angelis consideraba que este clérigo — que había sido expulsado en su momento de la Compañía de Jesús por cuestiones disciplinarias - había escrito esta obra calumniosa inspirado por «sentimientos rencorosos» apoyando a los enemigos de la orden contra sus antiguos correligionarios. ${ }^{33}$ Estos mitos antijesuíticos, de los cuales desconfiaba nuestro publicista, presentaban a los sacerdotes ignacianos como «hombres terribles y ambiciosos». ${ }^{34}$ Sin embargo estos nunca llegaron, según de Angelis, «a dar a sus asertos la evidencia que se necesita para producir el convencimiento». ${ }^{35}$

De la misma manera, el literato napolitano no estaba convencido de las acusaciones clásicas que señalaban a los jesuitas como los responsables del intento de asesinato del rey José I de Portugal en 1758 o los promotores de la rebelión de los indios guaraníes luego del Tratado de Límites. ${ }^{36}$ A lo largo de sus comentarios a los documentos sobre este importante acuerdo diplomático en el tomo cuarto de su Colección, Pedro de Angelis buscó desligar a los jesuitas de su participación en la Guerra Guaranítica. No sólo el escritor napolitano sostenía la inocencia de los ignacianos, sino que también señalaba a sus lectores el veloz ocaso que las misiones jesuitas sufrieron luego de la expulsión. Esta «decadencia, que no podía atribuirse á los estragos de la guerra, que nunca asoló aquella provincia, era efecto inmediato de los vicios, ó mas bien de la incompatibilidad del nuevo régimen que se estableció en los pueblos de Misiones», ${ }^{37}$ es decir, era

Pedro, Colección de obras y documentos relativos a la historia antigua y moderna de las provincias del Rio de la Plata ilustrados con notas y disertaciones por Pedro de Angelis, Buenos Aires, Imprenta del Estado, tomo tercero, 1836, p. I.

32. De Angelis menciona numerosas veces la obra antijesuítica de Ibáñez. Por ejemplo, en el «Discurso preliminar al diario del padre Henis» el napolitano critica la forma en que este clérigo manipulaba la información de los documentos que citaba para atacar a la Compañía. de Angelis, Pedro, «Discurso preliminar al diario del padre Henis» del Diario bistórico de la rebelión y guerra de los pueblos guaranís, situados en la costa oriental del río Uruguay, del año 1754 por el P. Tadeo Henis, en de Angelis, Pedro, Colección de obras y documentos relativos a la historia antigua y moderna de las provincias del Rio de la Plata ilustrados con notas y disertaciones por Pedro de Angelis, Buenos Aires, Imprenta del Estado, tomo tercero, 1836, p. VI.

33. Aunque reacio a creer en conspiraciones de Angelis consideraba que durante el siglo XVIII existió una «dictadura del espíritu filosófico» que presionó en las distintas cortes europeas e influyó en alguna medida en la desaparición de los jesuitas. de Angelis, Pedro, «Discurso preliminar» de la Historia del Paraguay, Rio de la Plata y Tucumán por el P. Guevara de la Compañía de Jesús, en de Angelis, Pedro, Colección de obras y documentos relativos a la historia antigua y moderna de las provincias del Rio de la Plata ilustrados con notas y disertaciones por Pedro de Angelis, Buenos Aires, Imprenta del Estado, tomo segundo, 1836, p. III.

34. Es interesante en este punto recordar la cercanía de de Angelis a Jules Michelet autor junto con Edgard Quinet de un famoso libro cargado de tópicos del antijesuitismo: Des Jesuites, Paris, Hachette, 1843. No obstante, de Angelis no parece haber seguido en este punto a estos académicos franceses. Para el antijesuitismo de Michelet y Quinet ver: Boutry, Philippe, «Edgar Quinet et le mythe jésuite en 1843: nova et vetera», en Fabre, Pierre-Antoine y Catherine Maire (eds.), Les Antijésuites: Discours, figures et lieux de l'antijésuitisme à l'époque moderne, Rennes, Presses Universitaires de Rennes, 2010, pp. 91-135.

35. De Angelis, Pedro, Historia del Paraguay..., cit., p. II.

36. Ibidem, pp. III-IV.

37. Ibidem, p. III. Sin embargo, de manera simultánea de Angelis consideraba que los indígenas habitantes de las misiones habían adquirido una dependencia tal al régimen económico instalado por los misioneros 
producto de la ausencia de los jesuitas, cuya destrucción dejó un gran vacío en América. ${ }^{38}$

A pesar de evitar explicaciones conspirativas, no por eso Pedro de Angelis suponía que los jesuitas eran completamente inocentes de su propia caída:

Los Jesuitas no conspiraron contra los tronos, sino contra sí mismos, ocupando en la organización política de los estados un lugar que no podían conservar sin invadir los derechos y las prerrogativas de la corona. «No puedo sujetar estos Padres (escribía al marqués de Pombal su hermano Carvalho de Mendoza, gobernador general de Marañón): su política y destreza son superiores a mis cuidados y a la fuerza de mis tropas. Han dado a los salvajes costumbres y hábitos que los unen a ellos indisolublemente». (...) El Rey mismo tenía que solicitar la cooperación de estos misioneros para llevar a efecto algunas de sus medidas, que no siempre los hallaban dispuestos a segundarlas. Así sucedió con el tratado de límites de 1750, que fue preciso anular por la tenacidad con que se opusieron a la evacuación y entrega de los pueblos fundados en la margen oriental del Uruguay. ${ }^{39}$

En este pasaje revelador el periodista napolitano expone claramente su postura respecto a sus concepciones sobre la relación entre el Estado y la Iglesia —y, por analogía, entre el Estado y la Compañía de Jesús-. La expulsión estuvo justificada no por el carácter moral de los sacerdotes o por algún maligno y secreto plan en el cual hubieran estado involucrados, sino a causa de no haber respetado el rol subordinado que, según de Angelis, debían tener respecto al poder estatal. Según este fragmento, la autonomía de los jesuitas en América había crecido a tal punto que no se consideraban a ellos mismos súbditos del rey de España. Asimismo, los ignacianos habían generado una relación de dependencia con los indígenas de tal tipo que cualquier política que la corona quisiera implementar en la región tenía que pasar bajo la aprobación de los misioneros.

Puede afirmarse que, de alguna manera, de Angelis creía en una forma muy atemperada del mito antijesuítico que afirmaba que los ignacianos habían creado dentro de las misiones un Estado independiente desde el cual se amenazaba la soberanía de las coronas ibéricas. ${ }^{40}$ Este publicista poseía una concepción regalista del poder en la cual la Iglesia

—calificado de monástico por el periodista napolitano- que no pudieron adaptarse a las trasformaciones que se provocaron por su ausencia. de Angelis, Pedro, «Proemio a la descripción de las misiones de Tarija», en la Descripción de las misiones, al cargo del colegio de Nuestra Señora de los Ángeles de la Villa de Tarija, por Fray Antonio Tamajuncosa, comisario y prefecto de dichas misiones, en de Angelis, Pedro, Colección de obras y documentos relativos a la historia antigua y moderna de las provincias del Rio de la Plata ilustrados con notas y disertaciones por Pedro de Angelis, Buenos Aires, Imprenta del Estado, 1836, tomo quinto, p. II.

38. De Angelis, Pedro, Historia del Paraguay..., cit., p. IV.

39. Ibidem, p. III.

40. Franco, José Eduardo, «Retórica de la conspiración y legitimación del combate a la Compañía de Jesús. Doctrina y mito de los jesuitas según el marqués de Pombal», en Alfaro Alfonso; Iván Escamilla; Ana Ibarra y Arturo Reynoso (eds.), Francisco Xavier Clavigero, un bumanista entre dos mundos. Entorno, pensamiento y presencia, México DF, Fondo de Cultura Económica, 2015, pp. 45-82. Aunque no llegaba a tales extremos conspirativos, de Angelis sostuvo en algunos pasajes de su obra que los ignacianos habían logrado fundar un «gobierno teocrático en América», de Angelis, Pedro, Historia del Paraguay..., cit., p. III. 
debía estar subordinada al Estado. Las ideas de Angelis estaban, de alguna manera, en consonancia con las de Juan Manuel de Rosas haciendo comprensible, entonces, su apoyo a la campaña rosista de presión difamatoria contra los jesuitas: los sacerdotes ignacianos debían estar subordinados al Estado y de no serlo debían sufrir el mismo destino que sus correligionarios durante el reinado de Carlos III.

Ahora bien, aunque haya criticado el poder excesivo que los jesuitas tuvieron a finales del siglo XVIII, de Angelis admiraba la obra evangelizadora de estos clérigos. Según el napolitano, uno de los primeros logros que los ignacianos alcanzaron en el continente fue atemperar rápidamente los efectos de la sangrienta conquista española:

La sanción religiosa impresa sobre esta conquista, los excesos que la habían manchado, y la sensación aun viva y palpitante producida por las enérgicas protestaciones del Obispo de Chiapas, atrajeron estos doctos cenobitas a las playas del Nuevo Mundo, arrancándoles de la palestra teológica, abierta con tanto ruido en Europa por los reformadores. Como el Iris cuando ahuyenta la tormenta, desplegando sus colores en un cielo aun cubierto de nublados, así la presencia de los misioneros ablandó los ánimos de los combatientes, infundiendo resignación en los unos, inspirando sentimientos más benévolos en los otros. (...) No contentos con haber disminuido el número de las víctimas, se propusieron echar los cimientos de una sociedad, fundada en los principios evangélicos, que se esforzaban de propagar entre sus neófitos. A la triste condición de esclavos substituyeron la de hombres, si no libres, al menos revestidos con el carácter de cristianos, y a la sombra de sus prácticas religiosas levantaron silenciosamente el edificio de una especie de república, en el seno mismo de la servidumbre y bajo el poder absoluto de los procónsules. ${ }^{41}$

En estas lineas extraídas de la introducción a la obra de Guevara se pueden observar varias cuestiones interesantes. Ante todo, la caracterización que realiza de Angelis de los jesuitas. Para este intelectual los ignacianos fueron, ante todo, académicos ilustrados quienes ante el salvajismo de los conquistadores españoles y las denuncias de Bartolomé de las Casas decidieron dedicarse a la evangelización de América mediante la reforma de las costumbres. La prédica jesuita logró ablandar los espíritus de los españoles y ayudó a aceptar la dominación en los indígenas. Según este esquema, a la pacificación de los pueblos siguió la construcción de una «república», la cual estaba en los primeros años de la evangelización subordinada al poder de la corona a diferencia de lo que sucedió en los años previos a la expulsión.

Fueron los saberes jesuíticos los que posibilitaron su obra evangélico-civilizadora en América y en las misiones Paraguay las cuales en 1768, según nuestro publicista, «habían alcanzado un grado de civilización, el mayor tal vez al que pueda elevarse un pueblo joven, y muy superior sin duda á todo cuando existía en el nuevo hemisferio». ${ }^{42}$ Estos saberes funcionaban como herramientas fundamentales de los misioneros para ganarse el favor de los indígenas. El caso del jesuita ingles Tomás Falkner es ilustrativo en este punto:

41. De Angelis, Pedro, Historia del Paraguay..., cit., pp. I-II.

42. Ibidem, p. IV. 
Los Jesuitas, que no sólo eran misioneros sino administradores, dieron a las tribus que se sometieron a su dirección, una especie de organización municipal, condecorando a sus jefes y caciques con el título y las atribuciones de corregidores. La mayor dificultad que encontraron fue acostumbrar a los indios a una vida más arreglada y laboriosa: (...)

Uno de los arbitrios, de que más se valieron los misioneros para acreditarse entre sus neófitos, era el ejercicio de la medicina. La primer prueba que daban de su habilidad en esta parte, bastaba a cimentar su crédito, y a extender su influjo más allá de lo que podían esperarlo de sus exhortaciones. (...)

Precisamente acababa de entrar en la Compañía Tomas Falkner, joven inglés que había acompañado a Buenos Aires un buque de Cádiz en calidad de cirujano. (...)

La extensión que habían dado los jesuitas a sus trabajos evangélicos mantenía en una actividad extraordinaria a sus operarios, y sobre todo a los que, como Falkner, estaban iniciados en los secretos de la higiene. Así es, que desde el día en que entró en la Compañía, hasta la supresión de esta orden, pasó del Paraguay a Tucumán, y de las pampas del sur a los bosques impenetrables del Chaco. ${ }^{43}$

Las prácticas médicas e higiénicas introducidas por Falkner fueron un gran aliciente para la llegada y permanencia de nuevos feligreses indígenas y motivo de imitación de otros sacerdotes de la orden. Sin embargo, no fueron los conocimientos médicos de Falkner los que llamaron la atención de de Angelis, sino los geográficos. Este sacerdote, como indica de Angelis a sus lectores, fue «el primero y el más exacto historiador de la región magallánica» y fue el que llenó el vacío informativo que existía sobre la región patagónica a finales del siglo XVIII. ${ }^{44}$ Las noticias que se podían extraer de las expediciones de Falkner eran de gran utilidad para conocer regiones sobre las cuales al momento de la edición de la Colección se conocía demasiado poco. Sin embargo, Falkner no fue el único de su orden que viajó a la Patagonia; los padres Quiroga y Lozano también se embarcaron en viajes hacia los territorios del sur:

43. De Angelis, Pedro, «Discurso preliminar a la traducción castellana de la Descripción de la Patagonia por Falkner», en la Descripción de Patagonia y de las partes adyacentes de la América meridional: que contiene una razón del suelo, producciones, animales, valles, montañas, ríos, lagunas, etc. de aquellos países. La religión, gobierno, política, costumbres y lengua de sus moradores, con algunas particularidades relativas a las Islas de las Malvinas, escrita en ingles por D. Tomás Falkner que residió cerca de 40 años en aquellas partes, en de Angelis, Pedro, Colección de obras y documentos relativos a la historia antigua y moderna de las provincias del Rio de la Plata ilustrados con notas y disertaciones por Pedro de Angelis, Buenos Aires, Imprenta del Estado, tomo primero, 1836, pp. I-III.

44. Ibidem, p. VI. El napolitano a pesar de admirar el saber geográfico de Falkner no podía dejar de recordar a sus lectores que este jesuita había conspirado en contra de España. Algunos fragmentos de su obra además de indicar la abundancia de recursos desaprovechados de la Patagonia incitaban a las naciones europeas - y particularmente a Inglaterra - a invadir el territorio español. La edición inglesa del libro de Falkner tuvo un impacto negativo en la Corte de Madrid —ya que mostraba el estado de desprotección en el que se encontraban algunos de los territorios españoles- y fue uno de los principales incentivos para la creación del Virreinato del Rio de la Plata. Bohn Martins, Maria Cristina, «Entre a escrita e a impressão: «A descrição da Patagônia», de Thomas Falkner», IHS. Antiguos jesuitas en iberoamérica, vol. 3, núm. 1, Córdoba, 2015, pp. 47 66. 
Cuando la corte de España mandó explorar los puntos accesibles de la costa patagónica, y los más a propósito para establecer poblaciones, á los pilotos Varela y Ramírez, que vinieron a bordo de La fragata San Antonio, se les asoció el P. Quiroga, cuyo diario sirvió al P. Lozano para redactar el que hemos publicado en el primer tomo de nuestra colección.

A su regreso de esta comisión, los PP. de la Compañía le encargaron levantara el mapa del territorio de Misiones: obra vasta y difícil, no solo por la naturaleza del terreno, sino por la falta de materiales y recursos. A pesar de estas trabas, aceptó el P. Quiroga este encargo, y después de haber determinado con una prolija exactitud la posición geográfica de los treinta pueblos de Misiones, y la de las ciudades de la Asumpcion, Corrientes, Santa Fé, Colonia, Montevideo y Buenos Aires, redactó su mapa con los datos que le suministraron las relaciones editas é inéditas de los misioneros, cuando no le fué posible adquirirlos personalmente.» ${ }^{45}$

En estas líneas podemos ver como los saberes de los misioneros jesuitas eran aprovechadas simultáneamente tanto por la Compañía como por la corona española. Sus habilidades cartográficas podían ser usadas tanto para la exploración de nuevas regiones como para facilitar el trabajo misional. La breve biografía que ofrece de Angelis de José Quiroga nos ofrece un poco más de información sobre esta doble utilidad de la erudición jesuita:

En uno de estos viajes trabó amistad con un religioso de la Compañía de Jesús, que pasaba a las Indias para tomar parte en los trabajos evangélicos de sus hermanos. La pintura que éste le hizo de su instituto, y de las ventajas que ofrecía a los que manifestaban celo y talentos, hicieron tan viva impresión en el ánimo del joven Quiroga que se decidió desde luego a tomar el hábito de San Ignacio. Sus superiores le incitaron a no abandonar sus estudios, en los que se hallaba bastante adelantado; y para que no le faltasen estímulos, le brindaron con una cátedra de matemática, que fundaron expresamente en el colegio de Buenos Aires.

Los servicios del nuevo profesor, provechosos a sus alumnos, lo fueron de un modo más trascendental para el Gobierno que, por falta de un facultativo, se hallaba a veces en la imposibilidad de resolver cuestiones importantes para el servicio público. Tal era la imposibilidad de los rumbos que debían seguirse en la medición de las tierras del égido de la ciudad, y que, por no haber sido bien determinados en las concesiones de los primeros pobladores, hacían dudar de sus límites quitando a los títulos de propiedad su principal requisito.» ${ }^{46}$

La presentación de las motivaciones de Quiroga para entrar en la Compañía de Jesús condice con la primera imagen que el periodista rosista había construido de los ignacianos: un grupo de sacerdotes movidos por las ansias de conocimientos. Desde joven este jesuita fue estimulado para continuar con estudios matemáticos que fueron de gran utilidad tanto para la orden como para la corona. Continuando en esta misma línea, a de Angelis le interesó destacar también como los misioneros de la Compañía estuvieron involucrados en

45. De Angelis, Pedro, «Noticias biográficas del padre José Quiroga», en la Descripción del río Paraguay, desde la boca del Xaurú hasta la confluencia del Paraná por el padre José Quiroga, en de Angelis, Pedro, Colección de obras y documentos relativos a la historia antigua y moderna de las provincias del Rio de la Plata ilustrados con notas y disertaciones por Pedro de Angelis, Buenos Aires, Imprenta del Estado, tomo segundo, 1836, p. II.

46. Ibidem, p. I-II. 
varios proyectos —organizados por el gobierno colonial— relacionados con la ocupación del territorio en el continente como, por ejemplo, en la conflictiva zona del Chaco. ${ }^{47}$

Fueron los conocimientos geográficos, cartográficos y matemáticos de los jesuitas del Paraguay una de las cosas que más interés generaron en Pedro de Angelis. Sin embargo, no menos importante era para el literato napolitano el saber histórico que poseían estos sacerdotes. Al prologar la obra de José Guevara afirma lo siguiente:

Los historiadores del Río de la Plata salieron casi todos del seno de la célebre Sociedad, que por cerca de dos siglos ejerció un influjo poderoso sobre los pueblos de estas regiones; y a los Schmidel, Guzmán, y Centenera, que describieron los hechos de la conquista que habían presenciado, sucedieron los padres Pastor, Montoya y del Techo, cuyos trabajos evangélicos la extendieron y afianzaron. ${ }^{48}$

El propio Guevara no fue sino uno de los últimos dentro de un gran listado de ilustres historiadores ignacianos, los cuales eran una referencia ineludible si se buscaba profundizar en el pasado del Rio de la Plata. Ahora bien, como ya hemos comentado previamente, no fue de Angelis el primero en reconocer la importancia de los trabajos producidos por los jesuitas para la reconstrucción de la historia local. El Ensayo de la Historia Civil del Paraguay del deán Funes estuvo basado en gran parte en la obra historiadores de la Compañía como Charlevoix, Lozano o Guevara. No obstante, en varias de las introducciones a las obras de la Colección de Angelis cuestiona el Ensayo de Funes y discute la forma en que este clérigo utilizó los datos extraídos de los jesuitas.

Más interesante aún es la concepción que de Angelis tenía sobre la importancia del conocimiento histórico para la construcción de la identidad de los pueblos modernos:

Los pueblos modernos no tienen que buscar su origen en los poetas y mitólogos; los historiadores son sus genealogistas, y del primer día de su existencia puede hablarse con tanto acierto como de un acontecimiento contemporáneo. Ya pasaron los tiempos en que para edificar ciudades tenían que bajar los dioses del Olimpo. Estas fábulas, inventadas para lisonjear la vanidad de los pueblos, aumentan el caudal de mentiras que nos han transmitido los antiguos, por más que se empeñen en acreditarlas los eruditos. ${ }^{49}$

47. De Angelis, Pedro, «Proemio a los proyectos de colonización del Chaco», en los Informes de D. Félix de Azara, sobre varios proyectos de colonizar el Chaco, en de Angelis, Pedro, Colección de obras y documentos relativos a la historia antigua y moderna de las provincias del Rio de la Plata ilustrados con notas y disertaciones por Pedro de Angelis, Buenos Aires, Imprenta del Estado, tomo cuarto, 1836, p. V. La región del Chaco es una de las que más llamó la atención de Angelis debido a lo indómito de su territorio —al que calificó de «sepulcro de misioneros»y a los numerosos intentos de colonización fallidos que llevó acabo el gobierno español. Ver, por ejemplo, de Angelis, Pedro, «Discurso preliminar al diario de Matorras», en el Diario de la expedición hecha en 1774 a los países del Gran Chaco, desde el fuerte del valle por Gerónimo Matorras, en de Angelis, Pedro, Colección de obras y documentos relativos a la historia antigua y moderna de las provincias del Rio de la Plata ilustrados con notas y disertaciones por Pedro de Angelis, Buenos Aires, Imprenta del Estado, tomo sexto, 1836, p. I.

48. De Angelis, Pedro, Historia del Paraguay..., cit., p. I.

49. De Angelis, Pedro, «Discurso preliminar a la fundación de Buenos Aires», en la Fundación de la ciudad de Buenos Aires con otros documentos de aquella época por Juan de Garay con otros documentos de aquella 
Son los historiadores, según de Angelis, los que ayudan a reconstruir los orígenes de los pueblos. Las obras de los sacerdotes ignacianos, entonces, funcionan como fuentes fundamentales a la hora de edificar la identidad de una joven nación con sólo un par de décadas de vida independiente.

Ahora bien, ¿cuál era el interés último de Pedro de Angelis en esta orden de sacerdotes eruditos? Como ya mencionamos, el napolitano era sensible a las vicisitudes de los sacerdotes ignacianos durante sus epopeyas misionales:

En este viaje científico desplegó un gran valor el jesuita Cardiel, y los detalles que da el padre Lozano sobre una excursión de este animoso misionero en el interior de la bahía, forman un trozo que no es posible leer sin emoción. «Cuando iban por la campaña sin camino», dice el redactor del viaje, «marchaba el Padre en medio, y los demás extendidos en ala a lo largo; y cuando por senda de indios (que la tuvieron muchas leguas) iba el Padre el primero, atemperando al paso de los menos fuertes, para que no les hiciesen caminar más de lo que podían. Llevaba al pecho un crucifijo de bronce, y en la mano un báculo, grabada en él una cruz». Estos pocos renglones son dignos de figurar en las páginas del Genio del Cristianismo del señor de Chateaubriand..$\gg^{50}$

Estas líneas son significativas porque en ellas de Angelis destaca simultáneamente el doble rol de estos sacerdotes: el de misioneros y científicos. No obstante, a lo largo de las distintas presentaciones de las obras de estos jesuitas en los tomos de la Coleccion de Angelis se encuentra mucho más interesado en esta última función que en las formas en que los jesuitas colaboraron con el avance del cristianismo en el continente americano. Es por esto que al prologar las obras relacionadas con la Compañía pone su atención mucho más en los datos que estas obras aportan sobre el territorio descripto que en cuestiones relacionadas con la evangelización. Los misioneros jesuitas fueron para el periodista napolitano no sólo conocedores directos de la geografía local, sino también, muchas veces, los primeros - y a veces los únicos- exploradores de las zonas más meridionales de América.

Una de las razones por las cuales los ignacianos se convirtieron para de Angelis en importantes fuentes de información es debido a que todavía persistía entrado el siglo XIX un gran desconocimiento sobre la geografía y la naturaleza del Río de la Plata y sus zonas aledañas. La queja por la falta de exploración de estos territorios es uno de los leitmotivs observables a lo largo de los comentarios de de Angelis a las obras de su Colección. Para el periodista rosista la principal causa de que una gran parte del continente americano estuviera debajo del velo de la ignorancia fue la pasividad y la avaricia de la corona española. Durante más de dos siglos de dominación colonial, ningún monarca estuvo interesado en explorar el territorio americano ni mucho menos permitir el ingreso de explora-

época, en Angelis, Pedro, Colección de obras y documentos relativos a la bistoria antigua y moderna de las provincias del Rio de la Plata ilustrados con notas y disertaciones por Pedro de Angelis, Buenos Aires, Imprenta del Estado, tomo tercero, 1836, p. I.

50. De Angelis, Pedro, Diario de un..., cit., p. I. 
dores de otras naciones europeas al continente. Sólo a mitad del siglo XVIII, bajo el reinado de los borbones se comenzaron a enviar expediciones científicas a América aunque las mismas fueron insuficientes. Estos tímidos intentos de exploración científica del continente se vieron, finalmente, interrumpidos a causa a los procesos de independencia en el continente y a las «disenciones civiles» que se generaron luego de los mismos. ${ }^{51}$ Este desconocimiento del territorio persistía lamentablemente, según de Angelis, hasta el momento de redacción de la Colección. La información sobre las provincias internas de la Confederación Argentina — como la Patagonia o el Chaco_ era todavía muy deficiente y aún una provincia como Mendoza — habitada desde la dominación colonial— era considerada por el napolitano como una de las más retiradas y desconocidas de la región. ${ }^{52}$

Esta ignorancia estaba comenzando a ser parcialmente solucionada durante la época en que de Angelis escribía gracias a las expediciones organizadas por Juan Manuel de Rosas. Entretanto, los saberes acumulados durante siglos por los jesuitas podían continuar siendo de utilidad, no sólo para complementar la información que proveían exploraciones contemporáneas, sino también para incentivar el desarrollo de futuros emprendimientos similares..$^{53}$ En varios pasajes de Angelis gustaba resaltar las formas en que Rosas estaba logrando en esos años ampliar el conocimiento de la región con sus campañas en la Provincia de Buenos Aires. En algunos casos el publicista napolitano hasta parecía motivar al gobierno rosista a expandir las fronteras hacia el sur y con ellas el saber geográfico:

Pero, si se exceptúan unas pocas tentativas que se hicieron para reconocer la costa patagónica, ningún otro trabajo científico acometió la Metrópoli para explorar el sur, en el largo periodo de más de tres siglos. Así es que gravita sobre los nuevos gobiernos todo el peso de esta inmensa tarea; y el que la emprenda, puede contar desde luego con los aplausos de los contemporáneos, y la admiración de la posteridad. ¿Qué mayor gloria que la de ensanchar los límites del orbe conocido, y de remover las pocas trabas que impiden llevar los beneficios de la civilización a una región desconocida? El viaje que publicamos es una prueba de lo que debe esperarse de un carácter activo y de un genio perseverante. ${ }^{54}$

Muchos detractores de la figura de Pedro de Angelis han señalado que el periodista napolitano —interesado sólo en los beneficios que la cercanía al poder suponía— sostuvo

51. De Angelis, Pedro, Descripción de Patagonia..., cit., p. I; de Angelis, Pedro, «Discurso preliminar a la descripción de Santa Cruz de la Sierra», en la Descripción geográfica y estadística de la provincia de Santa Cruz de la Sierra por Francisco de Viedma, su gobernador intendente, en Angelis, Pedro, Colección de obras y documentos relativos a la historia antigua y moderna de las provincias del Rio de la Plata ilustrados con notas y disertaciones por Pedro de Angelis, Buenos Aires, Imprenta del Estado, tomo tercero, 1836, p. I.

52. De Angelis, Pedro, «Proemio al diario de Hernández», en el Diario de un viage desde el fuerte de San Rafael del diamante, hasta el de San Lorenzo, en las puntas del rio Quinto, por D. Esteban Hernández; con otros documentos relativos al descubrimiento de un nuevo camino, desde Buenos Aires a San Agustín de Talca, por la Cordillera de los Andes, en de Angelis, Pedro, Colección de obras y documentos relativos a la bistoria antigua y moderna de las provincias del Rio de la Plata ilustrados con notas y disertaciones por Pedro de Angelis, Buenos Aires, Imprenta del Estado, tomo sexto, 1836, p. I.

53. De Angelis, Pedro, Diario de un..., cit., p. II; de Angelis, Pedro, Descripción de Patagonia..., cit., p. VI.

54. De Angelis, Pedro, Viage a su..., cit., pp. I-II. 
una conveniente relación de sumisión respecto a Juan Manuel de Rosas. Sin embargo, autores como Baltar han demostrado que el vínculo establecido por el académico napolitano fue mucho más complejo. En primer lugar, la formación cortesana antiguoregimental de de Angelis influyó directamente sobre sus concepciones del poder: para el napolitano se debía establecer un pacto de lealtad con cualquiera que estuviera en el gobierno — más allá de las ideas personales o partidarias - con el fin de conseguir lo que fuera de interés para ambas partes. Es por esto que de Angelis podía estar al servicio del poder rosista y aprovecharse simultáneamente del mismo para sus proyectos. Desde esta particular dinámica con el poder es que de Angelis cree poder sugerir, aconsejar y hasta presionar a Juan Manuel de Rosas a continuar con las expediciones a la Provincia de Buenos Aires y la Patagonia para ampliar el conocimiento geográfico de la región en la línea de su propia empresa cultural-académica. Uno de los objetivos últimos de la Colección, como señala Baltar, fue el de educar a sus lectores sobre la geografía y el pasado de la región; sin embargo, dentro de los lectores pensados encontraban para de Angelis tanto el público ilustrado o neófito de Buenos Aires como las propias autoridades políticas de la provincia, incluido el propio Rosas. Al mismo tiempo que alaba al gobernador de Buenos Aires por ampliar los conocimientos de región lo incita a continuar por ese camino para completar los saberes inacabados que proveyeron los jesuitas del Paraguay. ${ }^{55}$

\section{Conclusión. La Colección de de Angelis: ¿un intento de secularizar los saberes jesuitas?}

Si bien los saberes de los jesuitas estaban comenzando a desactualizarse en la época en que de Angelis publicó su colección, no por eso habían perdido utilidad, como hemos visto, para su proyecto académico. La muestra más cabal de esto es, justamente, la inclusión de varias obras de los sacerdotes ignacianos en la Colección. El renombre y la fama de erudición de la Compañía de Jesús — construida por los propios jesuitas durante siglos - influyeron en el napolitano a la hora de acercarse a sus miembros luego de su regreso a las costas de Buenos Aires. Fueron, no obstante, los datos sobre la naturaleza o la geografía locales que proveían las obras de los antiguos jesuitas del Paraguay los que motivaron su inclusión en la compilación de de Angelis.

Sin embargo, para usufructuar de estos saberes de Angelis tuvo que realizar una doble operación. En primer lugar, al publicar —y en muchos casos editar por primera vezescritos de los jesuitas del Paraguay, el publicista rosista retiró estos textos de sus circuitos de producción y circulación inicial. Pensados con un doble fin apologético y académico, muchos de estos trabajos fueron escritos por los miembros de la Compañía de Jesús para ensalzar el prestigio de la institución y colaborar con la formación de nuevos misioneros. Si bien la expulsión y la supresión de la Compañía transformaron hasta

55. Baltar, Rosalía, Letrados en tiempos..., cit., pp. 97, 130-133. 
casi disolverlos a estos circuitos institucionales internos, los jesuitas no dejaron de producir obras sobre sus experiencias en la misión. Participando en los debates intelectuales ilustrados, los jesuitas expulsos buscaron ofrecer al mismo tiempo información sobre el continente americano y defender a su perseguida orden. Pedro de Angelis extrae a todos estos trabajos de sus medios y sus objetivos originales, reinsertándolos en el contexto del Buenos Aires rosista.

En segundo lugar, de Angelis aprovechó de las obras de los ignacianos solamente lo que él consideró que era de utilidad para su proyecto académico. Al napolitano no le preocupaban ni los procesos de evangelización ni la defensa de la Compañía, sino la información del territorio que los jesuitas podían proveer de sus diferentes misiones y expediciones a lo largo de toda la región del Rio de la Plata. Estos recortes se observan sobre todo en las introducciones a los documentos publicados, pero también, por ejemplo, en la selección de fragmentos de la obra Historia del Paraguay de Charlevoix que de Angelis editó.

Nos arriesgamos, entonces, a afirmar que de Angelis realiza en su Colección un procedimiento de «secularización» de los saberes jesuíticos. Si tomamos como una definición posible de «secularización» la diferenciación de las diversas esferas (la Política, la Economía, la Ciencia, la Moral, etc.) de la vida social y su emancipación de la tutela de las instituciones religiosas, ${ }^{56}$ el ejercicio de resignificación de los saberes jesuíticos —a partir de la separación de los circuitos y usos originales - realizado por el literato napolitano podría ser englobado dentro de este proceso de larga duración.

El monopolio eclesiástico de la práctica científica y académica fue casi total durante la época colonial en América debido al control de los centros de estudio universitarios en el continente. El mismo comenzó a fracturarse a finales el siglo XVIII gracias a las transformaciones implementadas por los monarcas borbones con la creación de nuevas academias o colegios con espíritu ilustrado en distintas ciudades de América. En el Río de la Plata este tipo de instituciones no tuvieron tanta influencia como en otras partes del continente, sin embargo, se dio en la región durante las primeras décadas del siglo XIX — tanto antes como después del proceso de independencia local — un lento proceso de secularización en el campo académico. Como ejemplo, podemos citar lo sucedido con la Universidad de Córdoba. Luego de la expulsión de la Compañía de Jesús la administración de la misma pasó a manos de la orden franciscana; sin embargo, luego de varios años de reclamos a las autoridades reales, la misma fue transferida al clero secular en los últimos años de la colonia y, finalmente, luego del proceso de independencia a manos estatales. ${ }^{57}$ Sin embargo, este proceso de autonomización del campo académico de la esfera

56. Casanova, José, «Rethinking secularization: a global comparative perspective», Hedgehog Review, vol. 8, 2006, Charlottesville, pp. 7-22; Casanova, José, «The Secular, Secularizations, Secularisms», en Calhoun, Craig; Mark Juergensmeyer y Jonathan VanAntwerpen (eds.), Retbinking Secularism, New York, Oxford University Press, 2011, pp. 54-74.

57. De Asua, Miguel, La ciencia de Mayo. La cultura científica en el Rio de la Plata, 1800-1820, Buenos Aires, FCE, 2010, pp. 177-199; Troisi Melean, Jorge, Socios incómodos. Los franciscanos de Córdoba en una era de transformaciones (1767-1829), Rosario, Prohistoria, 2016, pp. 97-103. 
religiosa no fue necesariamente siempre lineal. Es interesante mencionar en este punto, por ejemplo, que durante la primera década postrevolucionaria varios clérigos letrados como Saturnino Segurola y Bartolomé Muñoz, entre otros, continuaron interviniendo activamente en debates científicos en la región. ${ }^{58}$

De Angelis retira en su Colección a los saberes jesuíticos del campo religioso transfiriéndolos al campo académico y despojándolos —y, de alguna manera, profanándolos_ 59 por sus finalidades originales. Sin despreciar las dotes evangelizadoras de los ignacianos, las minimiza y presta atención sólo a sus aportes en los campos del saber, reapropiándose de su erudición para su proyecto académico-político de conocimiento del territorio regional. Aún los méritos misionales de los ignacianos se secularizan: los sacerdotes que eran antes demandados para llevar las enseñanzas de Cristo a las profundidades de las selvas americanas son ahora reconocidos por sus dotes civilizatorios. ${ }^{60}$ Los aportes de los jesuitas al avance del conocimiento de la geografía del Rio de la Plata son separados de sus objetivos apologéticos y puestos a circular de manera autónoma en un nuevo circuito laico. ${ }^{61}$

Es posible comparar este objetivo de de Angelis de aislar a los saberes jesuíticos de sus objetivos originales con la actitud del gobierno rosista frente a los miembros de la Compañía de Jesús restaurada. Mientras que de Angelis utilizó a los trabajos de los antiguos e ilustres jesuitas de la provincia del Paraguay para sus objetivos académicos, Juan Manuel de Rosas, su protector, buscó aprovecharse de las praxis educativas y religiosas ignacianas. Aunque sin éxito, quiso poner a los jesuitas bajo el control estatal de una manera similar a lo que había logrado con una parte de la Iglesia bonaerense. En este caso, la esfera política no sólo se autonomiza de la eclesiástica, sino que busca subsumirla y dominarla. Podemos afirmar, entonces, que en el Río de la Plata el proceso de secularización no se desenvolvió de igual manera en cada una de las distintas esferas de la vida social, aunque queda todavía mucho que explorar de estos procesos. ${ }^{62}$

58. Ibidem, pp. 73-92, 155-176.

59. Agamben, Giorgio, Profanaciones, Buenos Aires, Adriana Hidalgo editora, 2009, pp. 97-119.

60. La idea de que los jesuitas eran portadores de una serie de saberes científicos que facilitarían la llegada de la civilización fue un topos común en el siglo XIX en varios países de América. El mismo era esgrimido para justificar la restauración de la Compañía. Paradójicamente, eran los miembros de los partidos católicos locales los que utilizaron este tipo de argumentos secularizados. Por ejemplo, para colaborar con la restauración de los jesuitas en Chile se reimprimieron en 1844 una serie de artículos de la prensa colombiana que alababan los conocimientos científicos, lingüísticos y misionales de los jesuitas los cuales serían no sólo útiles para civilizar a los pueblos aborígenes, sino que también para la educación de las élites locales. Restablecimiento de la Compañía de Jesús en la Nueva Granada o Colección de piezas relativas a la bistoria de los jesuitas y su restablecimiento, Santiago de Chile, Imprenta del Estado, 1844, pp. 27, 15, 55-56.

61. Algo similar sucedió en los siglos XVII y XVIII en Europa con la información que los jesuitas enviaban al continente sobre sus misiones en China y la filosofía moral confuciana. Mientras que los misioneros describían una avanzada y civilizada sociedad oriental compatible con los principios cristianos, los filósofos y pensadores ilustrados europeos utilizaban esta misma información para teorizar sobre la posibilidad de construir una sociedad basada en una moral no religiosa. Mungello, David, Curious Land: Jesuit Accomodation and the Origins of Sinology, Honolulu, Hawaii University Press, 1989.

62. Ayrolo, Valentina; Maria Elena Barral y Roberto Di Stefano, «Introducción», en Ayrolo, Valentina; 
El campo académico-científico, por ejemplo, tardó varias décadas para consolidarse de manera autónoma en la región. Todavía en la década del treinta del siglo XIX Pedro de Angelis tenía que utilizar como fuentes viables de información sobre el territorio del Rio de la Plata los relatos de misioneros jesuitas del Paraguay del siglo anterior. Será necesario seguir indagando de qué manera los jesuitas y sus saberes fueron resignificados — dentro del contexto más general de la Iglesia bonaerense y argentina- a lo largo del siglo por los diversos actores para comprender de qué manera se fueron desarrollando el (los) proceso(s) de secularización en la región.

\section{Fuentes impresas}

de Angelis, Pedro, Colección de obras y documentos relativos a la historia antigua y moderna de las provincias del Rio de la Plata ilustrados con notas y disertaciones por Pedro de Angelis, Buenos Aires, Imprenta del Estado, 6 tomos, 1836-37.

Falkner, Thomas, A Description of Patagonia and the Adjoining Parts of South America: containing an Account of the Soil, Produce, Animals, Values, Mountains, Rivers, Lakes, and etc. of those Countries; the Religion, Government, Policy, Customs, Dress, Arms, and Language of the indian Inhabitants; and some Particulars relating to Falklands Islands, Londres, Hereford, 1774.

Funes, Gregorio, Ensayo de Historia Civil del Paraguay, Buenos-Ayres y Tucumán, Buenos Aires, Imprenta Gandarillas, 1816.

Restablecimiento de la Compañia de Jesús en la Nueva Granada o Colección de piezas relativas a la historia de los jesuitas y su restablecimiento, Santiago de Chile, Imprenta del Estado, 1844.

\section{Bibliografía}

Agamben, Giorgio, Profanaciones, Buenos Aires, Adriana Hidalgo editora, 2009, pp. 97-119. Ayrolo, Valentina; Maria Elena Barral y Roberto Di Stefano, «Introducción», en Ayrolo, Valentina; Maria Elena Barral y Roberto Di Stefano (coords.), Catolicismo y Secularización. Argentina, primera mitad del siglo XIX, Buenos Aires, Editorial Biblos, 2012, pp. 9-13.

Baltar, Rosalía, Letrados en tiempos de Rosas, Mar del Plata, Eudem, 2012.

Batllori, Miguel, La cultura hispano-italiana de los jesuitas expulsos, Madrid, Gredos, 1966.

Betrán Moya, José Luis (ed.), La Compañia de Jesús y su proyección en el mundo hispánico durante la Edad Moderna, Madrid, Silex, 2010.

Bohn Martins, Maria Cristina, «Entre a escrita e a impressao: «A descricao da Patagonia» de Thomas Falkner», IHS. Antiguos jesuitas en iberoamerica, vol. 3, n. ${ }^{\circ}$ 1, 2015, Córdoba, pp. 47-66.

Maria Elena Barral y Roberto Di Stefano (coords.), Catolicismo y Secularización. Argentina, primera mitad del siglo XIX, Buenos Aires, Editorial Biblos, 2012, pp. 9-13. 
Boutry, Philippe, «Edgar Quinet et le mythe jésuite en 1843: nova et vetera», en Fabre, Pierre-Antoine; Catherine Maire (eds.), Les Antijésuites: Discours, figures et lieux de l'antijésuitisme à l'époque moderne, Rennes, Presses Universitaires de Rennes, 2010, pp. 91-135.

Cañízares Esguerra, Jorge, Cómo escribir la historia del Nuevo Mundo. Historiografías, epistemologías e identidades en el mundo del Atlántico del siglo XVIII, México DF, Fondo de Cultura Económica, 2007.

Casanova, José, «The Secular, Secularizations, Secularisms», en Calhoun, Craig; Mark Juergensmeyer y Jonathan VanAntwerpen (eds.), Retbinking Secularism, New York, Oxford University Press, 2011, pp. 54-74.

—, «Rethinking secularization: a global comparative perspective», Hedgehog Review, v. 8, Spring/ Summer 2006, Charlottesville, pp. 7-22.

Castagnino, Raul, Rosas y los jesuitas, Buenos Aires, Pleamar, 1970.

De Asua, Miguel, La ciencia de Mayo, La cultura científica en el Rio de la Plata, 1800-1820, Buenos Aires, Fondo de Cultura Económica, 2010.

Di Stefano, Roberto, «El antijesuitismo porteño del siglo XIX», en Monreal, Susana; Sabina Pavone y Guillermo Zermeño (eds.), Antijesuitismo y filojesuitismo. Dos identidades ante la Restauración, México DF, Universidad Iberoamericana, 2014, pp. 167-190.

—, «El laberinto religioso de Juan Manuel de Rosas», Anuario de Estudios Americanos, núm. 63-1, 2006, Sevilla, pp. 19-50.

Esteban, Rafael, Como fue el conflicto entre los Jesuitas y Rosas, Buenos Aires, Plus Ultra, 1971.

Feingold, Mordechai, Jesuit Science and the Republic of Letters, Cambridge, The MIT Press, 2003.

Franco, José Eduardo, «Retórica de la conspiración y legitimación del combate a la Compañía de Jesús. Doctrina y mito de los jesuitas según el marqués de Pombal», en Alfaro, Afonso, Ivan Escamilla, Ana Ibarra, Arturo Reynoso (eds.), Francisco Xavier Clavigero, un bumanista entre dos mundos. Entorno, pensamiento y presencia, México DF, Fondo de Cultura Económica, 2015, pp. 45-82.

Furlong, Guillermo, José Sánchez Labrador y su «Yerba Mate» (1774), Buenos Aires, Librería del Plata, 1960.

—, Pedro Lozano y sus «Observaciones a Vargas» (1750), Buenos Aires, Libreria del Plata, 1959.

—, El Padre José Quiroga, Buenos Aires, Peuser, 1930.

Giard, Luce (dir.), Les jésuites à la Renaissance. Système éducatif et production du savoir, Paris, PUF, 1995.

Grenon, Pedro, Los Funes y el P. Juárez, Córdoba, La Guttemberg, 1920.

Guasti, Niccolo, L'esilio italiano dei gesuiti spagnoli. Identita, controllo sociale e pratiche culturali (1767-1798), Roma, Edizioni di Storia e Letteratura, 2006.

Harris, Steven, «Mapping Jesuit Science: The Role of Travel in the Geography of Knowledge», en O'Malley S. J., John; Gauvin Alexander Bailey; Steven J. Harris y Frank Kennedy S. J. (eds.), The Jesuits. Culture, Science and the Arts, 1540-1773, Toronto, University of Toronto Press, 1999, pp. 212-240.

Lida, Miranda, Dos ciudades y un deán. Biografía de Gregorio Funes, 1749-1829, Buenos Aires, Eudeba, 2006.

Mercado, Juan Carlos, «Pedro de Angelis y la historia intelectual argentina de la primera mitad del siglo XIX», Hesperia. Anuario de filología hispánica, núm. XVI-2, 2013, pp. 59-72.

Michelet, Jules y Quinet, Edgard, Des Jesuites, Paris, Hachette, 1843. 
Mungello, David, Curious Land: Jesuit Accomodation and the Origins of Sinology, Honolulu, Hawaii University Press, 1989.

Perez, Rafael, La Compañia de Jesús restaurada en la República Argentina y Chile, el Uruguay y el Brasil, Barcelona, Imprenta de Henrich, 1901.

Revuelta González, Manuel, «Capítulo VIII. Sesenta años de reapariciones inestables (1815-1874)» en Egidio, T., Los jesuitas en España y el mundo hispánico, Marcial Pons, Madrid, 2004, pp. 291 312.

Ruggeri, Paula, «Estudio preliminar», en de Angelis, Pedro, Archivo Americano y espíritu de la prensa del mundo. Primera Serie 1843-1847, Buenos Aires, Ediciones Biblioteca Nacional, 2009, pp. 9-36.

Sabor, Josefa, Pedro de Angelis y los orígenes de la bibliografía argentina. Ensayo bio-bibliográfico, Buenos Aires, Ediciones Solar, 1995.

Troisi Melean, Jorge, Socios incómodos. Los franciscanos de Córdoba en una era de transformaciones (1767-1829), Rosario, Prohistoria, 2016.

Wallace O. P., William, «Jesuit Influences on Galileo’s Science», en O’Malley S. J., John; Gauvin Alexander Bailey; Steven J. Harris y Frank Kennedy S. J. (eds.), The Jesuits II. Culture, Science and the Arts, 1540-1773, Toronto, University of Toronto Press, 2006, pp. 314-335.

Wilde, Guillermo (ed.), Saberes de la conversión. Jesuitas, indigenas e imperios coloniales en las fronteras de la Cristiandad, Buenos Aires, Ediciones SB, 2011.

—, Religión y Poder en las misiones de guaraníes, Buenos Aires, Ediciones SB, 2009. 